\title{
Severe hyperphosphatemia after oral laxative administration in a 7-year-old patient
}

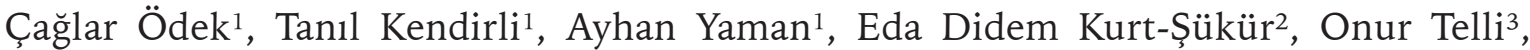 \\ Berk Burgu ${ }^{3}$, Z. Birsin Özçakar ${ }^{2}$ \\ Divisions of ${ }^{1}$ Pediatric Critical Care, and ${ }^{2}$ Pediatric Nephrology, Department of Pediatrics, ${ }^{3}$ Division of Pediatric Urology, \\ Department of Urology, Ankara University Faculty of Medicine, Ankara, Turkey. \\ E-mail: odek@ankara.edu.tr \\ Received: 13 February 2015, Accepted: 21 October 2015
}

SUMMARY: Ödek Ç, Kendirli T, Yaman A, Kurt-Şükür ED, Telli O, Burgu B, Özçakar ZB. Severe hyperphosphatemia after oral laxative administration in a 7-year-old patient. Turk J Pediatr 2016; 58: 116-118.

Sodium phosphate based laxatives are commonly used for constipation and pre-procedural bowel cleansing. Phosphate intoxication related with these preparations is well recognized. Herein, we present a case of severe hyperphosphatemia and seizure in a 7-year-old male patient after administration of an oral sodium phosphate based laxative. At the time of admission, serum phosphorus level was $25.6 \mathrm{mg} / \mathrm{dl}$. Aggressive fluid therapy was started. Although serum phosphorus level decreased to $20.9 \mathrm{mg} / \mathrm{dl}$ eight hours after admission, hemodialysis was performed because of the preexisting renal disease and declined glomerular filtration rate. Serum phosphorus level and blood gas analysis returned to normal after hemodialysis and the patient was discharged on hospital day two. In conclusion, sodium phosphate based laxatives should be used carefully in patients with preexisting renal diseases. Intravenous hydration and correction of hypocalcemia are important components of treatment. Hemodialysis is indicated in patients with renal failure.

Key words: hyperphosphatemia, hypocalcemia, metabolic acidosis, sodium phosphate, laxative.

Oral sodium phosphate $(\mathrm{NaP})$ based laxatives are frequently used for bowel cleansing or relief of constipation in children and adolescents. These preparations can cause mild electrolyte disorders that usually resolve within 24 hours. The most common electrolyte imbalance is hyperphosphatemia ${ }^{1}$. However, some individuals are prone to developing severe hyperphosphatemia such as patients with decreased renal function or poor gastrointestinal transit ${ }^{2}$. Herein, we present a case of severe hyperphosphatemia in a 7-year-old patient after administration of an oral $\mathrm{NaP}$ based laxative.

\section{Case Report}

A 7-year-old male patient was referred to our pediatric intensive care unit (PICU) with lethargy and seizure. He was diagnosed with meningomyelocele in the newborn period and a surgical repair had been performed. His medical history also included hydrocephalus, paraplegia, and neuropathic bladder. Despite clean intermittent catheterization and anticholinergic drugs, he had high-grade vesicoureteral reflux and hydronephrosis. An augmentation enterocystoplasty was planned at pediatric urology clinic of our institution. The night before the procedure, a pediatric-sized $45 \mathrm{ml} \mathrm{NaP}$ based oral laxative, containing $48 \mathrm{~g}$ of monobasic and $18 \mathrm{~g}$ of dibasic $\mathrm{NaP}$ per $100 \mathrm{ml}$, was administered for his bowel preperation. Three hours after administration, the patient developed lethargy and generalized tonic clonic seizure. Intravenous diazepam was administered for seizure and he was immediately transferred to our PICU. At the time of PICU admission, the level of consciousness was slightly depressed. Physical examination revealed growth retardation, mild hydrocephalus, and paraplegia due to his primary diagnosis. He also had mild to moderate dehydration. His vital signs 
were as follows: heart rate, 146 beats per minute; respiratory rate, 42 per minute; oxygen saturation, $98 \%$; blood pressure, 92/50 $\mathrm{mmHg}$. Pediatric Risk of Mortality III (PRISM-III) ${ }^{3}$ and Pediatric Logistic Organ Dysfunction (PELOD) ${ }^{4}$ scores were 6 and 0 , respectively. Laboratory data revealed: blood urea nitrogen, $9 \mathrm{mg} / \mathrm{dl}$; creatinine, $0.79 \mathrm{mg} / \mathrm{dl}$ (basal creatinine was $0.42 \mathrm{mg} / \mathrm{dl}$ ); uric acid, $7 \mathrm{mg} / \mathrm{dl}$; sodium, 144 $\mathrm{mEq} / \mathrm{L}$; potassium, $5.1 \mathrm{mEq} / \mathrm{L}$; phosphorus, $25.6 \mathrm{mg} / \mathrm{dl}$; calcium, $7.7 \mathrm{mg} / \mathrm{dl}$. Blood gas analysis showed a decompensated metabolic acidosis ( $\mathrm{pH}$ : 7.04, $\mathrm{pCO}_{2}: 24.9 \mathrm{mmHg}, \mathrm{pO}_{2}$ : $229 \mathrm{mmHg}, \mathrm{SaO}_{2}: 99.1 \%, \mathrm{HCO}_{3}: 6.6 \mathrm{mEq} / \mathrm{L}$, BE: $-23.1 \mathrm{mEq} / \mathrm{L})$ with a high anion gap (35.4 $\mathrm{mEq} / \mathrm{L})$. Estimated glomerular filtration rate (eGFR) according to Schwartz equation was $44 \mathrm{ml} / \mathrm{min} / 1.73 \mathrm{~m}^{2}$. The result of computed tomography scan of the head, performed because of the lethargy and seizure, was normal. Electrocardiogram monitoring was normal except for sinus tachycardia.

Intravenous (IV) fluid therapy was started with $20 \mathrm{ml} / \mathrm{kg}$ isotonic sodium chloride infusion over one hour and continued with maintenance $+10 \%$ deficit. Urine output was maintained over $2 \mathrm{ml} / \mathrm{kg}$ per hour. Eight hours after the initiation of aggressive fluid therapy, serum phosphorus and calcium levels were 20.9 $\mathrm{mg} / \mathrm{dl}$ and $4.7 \mathrm{mg} / \mathrm{dl}$, respectively (Fig. 1). We decided to perform hemodialysis (HD) considering the fact that our patient also had an underlying renal disease and eGFR was declined. The patient received HD through a femoral 7 French dual lumen HD catheter using polysulfone low flux dialyzer (Fresenius F3 dialyzer, $0.4 \mathrm{~m}^{2}$, Braun Dialog hemodialysis machine) and dialysate $(\mathrm{K}, 2 \mathrm{mEq} / \mathrm{L} ; \mathrm{Ca}, 1.5$ $\left.\mathrm{mEq} / \mathrm{L} ; \mathrm{HCO}_{3}, 33 \mathrm{mEq} / \mathrm{L}\right)$. Blood flow rate was $130 \mathrm{ml} / \mathrm{min}$ and duration of HD was 3 hours. Serum phosphorus and calcium levels returned to normal after HD (Fig. 1). The result of blood gas analysis was normal and after an uneventful course, the patient was discharged on PICU day two.

\section{Discussion}

Sodium phosphate based laxatives are commonly used for constipation and preprocedural bowel cleansing because of their hyperosmolar characteristics. These preperations are recognized as safe but not without risk. NaP preparations are associated with renal toxicity, cardiac arrhythmias, ischemic bowel injury, and changes in electrolyte levels ${ }^{1}$. Hypokalemia, mild hypernatremia, and hypocalcemia can be seen but the most common electrolyte imbalance is hyperphosphatemia ${ }^{5}$. Almost all patients who take the standart dose of $\mathrm{NaP}$ will develop hyperphosphatemia; the average increase in serum phosphorus level is $1-1.3 \mathrm{mEq} / \mathrm{L}^{1}$. Mild, asymptomatic hyperphosphatemia up to $2-3$ times above normal phosphorus levels occur in $25 \%$ of individuals with normal renal function ${ }^{6}$. However, in the presence of risk factors such as slow gastrointestinal transit, increased intestinal permeability, preexisting electrolyte disturbances, inadequate fluid intake or renal diseases, individuals are prone to develop severe and symptomatic hyperphosphatemia ${ }^{2}$. Our patient had both chronic constipation and renal disease as risk factors.

Phosphate intoxication can be life-threatening and fatal cases have been reported in both children and adults ${ }^{2,7}$. An acute rise in plasma phosphorus is generally accompanied by hypocalcemia, which accounts for most of the symptomatology. Neuromuscular and neurological symptoms such as muscle cramps, carpopedal spasm, laryngeal spasm, confusion, and seizure are related to hypocalcemia ${ }^{8}$. Hypocalcemia may also affect cardiac rhythm by prolonging the QT interval and may cause fatal arrhythmias ${ }^{2}$. As a result of high calciumphosphorus $\left(\mathrm{CaxPO}_{4}\right)$ product, tubular calcium phosphate deposits may cause nephrocalcinosis and renal failure ${ }^{1}$.

The treatment of phosphate intoxication mainly focuses on correction of fluid status and normalization of electrolytes. Some of the patients may require intensive care unit

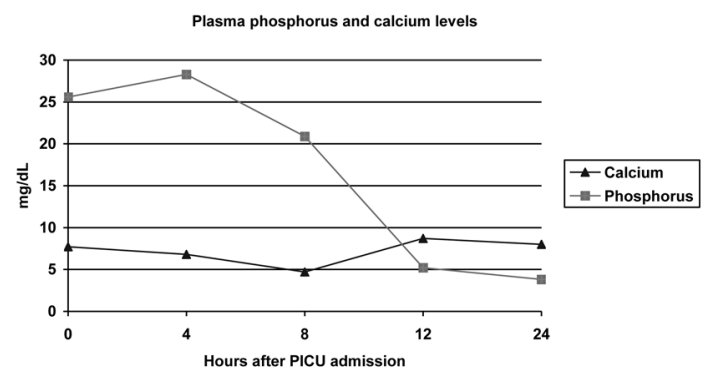

PICU, pediatric intensive care unit; Hemodialysis was started at the 8th hour of PICU admission

Fig. 1. Plasma levels of phosphorus and calcium as recorded up to 24 hours after PICU admission 
admission for close monitoring, inotropic and respiratory support ${ }^{9}$. Initial fluid resuscitation is crucial to restore adequate perfusion and glomerular filtration rate because acute hyperphosphatemia generally resolves within few hours if renal function is intact ${ }^{10}$. However, the excretory potential of the kidneys is limited in some patients because of a preexisting renal disease or acute renal failure related with nephrocalcinosis due to high $\mathrm{CaxPO}_{4}$ product $^{9}$. Urgent HD is indicated and might be life saving in these patients. If urine output is preserved, a single HD therapy may be sufficient because rebound hyperphosphatemia after HD was not reported in patients with severe hyperphosphatemia due to $\mathrm{NaP}$ based laxatives ${ }^{8}$. In our patient, serum phosphorus level dramatically decreased to normal after HD and we did not observe rebound hyperphosphatemia.

Another important component in the treatment of hyperphosphatemia is the correction of hypocalcemia, but calcium replacement therapy is a dilemma in these patients because of high $\mathrm{CaxPO}_{4}$ product $^{8}$. For concern of metastatic calcification through calcium phosphate precipitation in the kidney and other tissues, parenteral calcium replacement should be administered in patients with neuromuscular symptoms and cardiac arrhythmias ${ }^{2}$. We did not administer IV calcium to our patient because the $\mathrm{CaxPO}_{4}$ product was very high $\left(197.12 \mathrm{mg}^{2} /\right.$ $\mathrm{dL}^{2}$ ) and he had no neuromuscular symptoms or cardiac arrhytmias after PICU admission.

$\mathrm{NaP}$ based laxatives, even in standard doses, may lead to phosphate intoxication. Hyperphosphatemia and resultant hypocalcemia can be life threatening and even fatal. These agents should be used carefully especially in patients with preexisting renal diseases. Intravenous hydration should be the first line of treatment. Direct removal of the phosphate by HD is indicated in patients with renal failure. Intravenous calcium administration is crucial in patients with neuromuscular symptoms and cardiac arrhythmias.

\section{REFERENCES}

1. Adamcewicz M, Bearelly D, Porat G, Friedenberg FK. Mechanism of action and toxicities of purgatives used for colonoscopy preparation. Expert Opin Drug Metab Toxicol 2011; 7: 89-101.

2. Szoke D, Dolci A, Genderini A, Panteghini M. Fatal electrolyte abnormalities following enema administration. Clin Chem 2012; 58: 1515-1518.

3. Pollack MM, Patel KM, Ruttimann UE. PRISM III: an updated Pediatric Risk of Mortality score. Crit Care Med 1996; 24: 743-752.

4. Leteurtre S, Martinot A, Duhamel A. Validation of the paediatric logistic organ dysfunction (PELOD) score: prospective, observational, multicentre study. Lancet 2003; 362: 192-197.

5. Ainley EJ, Winwood PJ, Begley JP. Measurement of serum electrolytes and phosphate after sodium phosphate colonoscopy bowel preparation: an evaluation. Dig Dis Sci 2005; 50: 1319-1323.

6. Lieberman D, Ghormley J, Flora K. Effects of oral sodium phosphate colon preparation on serum electrolytes in patients with normal serum creatinine. Gastrointest Endosc 1995; 43: 467-469.

7. Ismail EA, Al-Mutairi G, Al-Anzy H. A fatal small dose of phosphate enema in a young child with no renal or gastrointestinal abnormality. J Pediatr Gastroenterol Nutr 2000; 30: 220-221.

8. Arıkan H, Güler D, Birdal G, Et al. Massive hyperphosphatemia in a patient with neuronal intestinal dysplasia after bowel preparation with oral sodium phosphate. Ren Fail 2013; 35: 875-878.

9. Ladenhauf HN, Stundner O, Spreitzhofer F, Deluggi S. Severe hyperphosphatemia after administration of sodium-phosphate containing laxatives in children: case series and systematic review of literature. Pediatr Surg Int 2012; 28: 805-814.

10. Malberti F. Hyperphosphatemia: treatment options. Drugs 2013; 73: 673-688. 